\title{
Freund's complete adjuvant effect on BALB/c mice: an insight into inflammation and oxidative stress after immunity challenge
}

\author{
Pohanka $\mathrm{M}^{1,2}$, Vobornikova $\mathrm{I}^{1}$, Fusek $\mathrm{J}^{3}$ \\ Faculty of Military Health Sciences, University of Defence, Hradec Kralove, Czech Republic. \\ miroslav.pohanka@gmail.com
}

\begin{abstract}
Freund's complete adjuvant (FCA) is a mean used for improving immunization efficacy in experiments and veterinary medicine. Despite high efficacy, it is not used in human vaccination due to number of adverse effects. Arthritis can be an example of a typical adverse consequence. In this work, we decided to investigate the link between oxidative stress and inflammation in animals exposed to FCA. BALB/c mice received either saline or FCA in doses 10-50 $\mu \mathrm{l}$ and were euthanized from one to three days after infection. Interleukins (IL) IL-2, IL-4 and tumor necrosis factor $\alpha(T N F-\alpha)$ were determined in plasma. Ferric reducing antioxidant power (FRAP), malondialdehyde by thiobarbituric acid reactive substances assay (TBARS), reduced glutathione (GSH) and caspase-3 were measured in livers, muscles and other organs. We determined significant effect of FCA on TBARS and GSH in the livers. Beside this, TBARS were altered in muscles as well. Inflammation was confirmed by increased level of TNF- $\alpha$. Taking the results into account, we infer that the harmful effect of FCA is mediated not only by inflammation but also by oxidative. This should be considered when pathological consequences of FCA are scored (Fig. 4, Ref. 21). Text in PDF www.elis.sk.

KEY WORDS: adjuvant, oxidative stress, inflammation; glutathione, immunity, vaccination, arthritis.
\end{abstract}

\section{Introduction}

Freund's complete adjuvant (FCA) is a suspension of Mycobacterium tuberculosis in mineral oil used for challenging immunity. Despite its high efficacy in vaccination, FCA has adverse effect and application of FCA is connected with an unwanted distress (1). Firstly, application of FCA causes pro-inflammatory reaction of immune system with growing inflammatory cytokines release $(2,3)$. Several adverse effects by FCA application can arise as a result of inflammation. FCA induced arthritis $(4,5)$, hyperalgesia (6) and alteration in nutrients utilization (7) can be introduced as important adverse effects. Apart from the adverse effects, FCA was found to be able to ameliorate progression of Parkinson disease and type 1 diabetes mellitus in an experiment on model laboratory animals $(8,9)$. The effect is mediated by an inflammatory stimulus and it was neither confirmed nor studied in humans hence the conclusions of the quoted papers have to be considered as preliminary one.

Though pathologies related to FCA were described and identified to an inflammatory reaction, a complex look into the issue is not currently available and principles how FCA initiates the pathologic consequences remain undiscovered. In this study, we

${ }^{1}$ Faculty of Military Health Sciences, University of Defence, Trebesska 1575, CZ-500 01 Hradec Kralove, Czech Republic, ${ }^{2}$ Department of Geology and Pedology, Mendel University in Brno, Czech Republic, and ${ }^{3} \mathrm{Fac}-$ ulty of Health Studies, University of Pardubice, Czech Republic

Address for correspondence: M. Pohanka, MD, Faculty of Military Health Sciences, University of Defence, Trebesska 1575, CZ-500 01 Hradec Kralove, Czech Republic have decided to investigate the pathologic consequences associated with FCA by examination of standard immunochemical markers and markers of oxidative stress. We hypothesize the involvement of FCA in the markers level and an impact of FCA on the related processes including oxidative homeostasis.

\section{Material and methods}

\section{Laboratory animals}

Female BALB/c mice from Velaz (Unetice, Czech Republic) were used and in total 120 mice were included into the experiment. The mice underwent three weeks lasting quarantine and they were eight weeks old at the beginning of the experiment. During the whole experiment, the mice were kept in an air conditioned room with steady temperature $\left(22 \pm 2{ }^{\circ} \mathrm{C}\right)$, humidity $(50$ $\pm 10 \%$ ) and light/dark period each lasting 12 hours. Experiment on laboratory animals was both permitted and supervised by the ethical committee at Faculty of Military Health Sciences (Hradec Kralove, Czech Republic).

The animals were exposed to either saline (controls) or FCA in a dose 10, 20 or $50 \mu 1$. The dose of FCA $50 \mu 1$ was chosen as an upper one not initiating serious pathological consequence or serious distress in the animals $(10,11)$. FCA was received from Sigma-Aldrich company via a branch in Prague, Czech Republic. The FCA contained $1 \mathrm{mg}$ of Mycobacterium tuberculosis (H37RA; American type of culture collection 25177) per $1 \mathrm{ml}$ of mixture composed from $0.15 \mathrm{ml}$ mannide monooleate and $0.85 \mathrm{ml}$ of paraffin oil. The animals were divided into 4 groups, 30 animals each. Animals in the group No. 1 received $100 \mu 1$ of saline, in the group 
No. 2 received $100 \mu 1$ mixture containing $10 \mu 1$ of FCA with 90 $\mu \mathrm{l}$ of saline, No. 3 received $100 \mu \mathrm{l}$ of mixture composed from 20 $\mu 1$ of FCA and $80 \mu 1$ of saline, and animals in the last group No. 4 each received $100 \mu 1$ of mixture composed from $50 \mu 1$ of FCA and $50 \mu 1$ of saline. The mixtures were applied intramuscularly (i.m.) into left posterior limb. From each group, 10 animals were euthanized one day, another 10 animals two days and the last 10 animals three days after mixtures application. The animals were sacrificed under $\mathrm{CO}_{2}$ anesthesia when jugular vein was cut in an animal in deep unconsciousness.

\section{Samples}

Blood from jugular vein was taken directly into lithium heparin treated tubes (Dialab, Prague, Czech Republic). After collection, the blood was centrifuged at $1,000 \times \mathrm{g}$ for 5 minutes and fresh plasma was separated and stored at $-80{ }^{\circ} \mathrm{C}$ until performance of assay. Cut of frontal lobe cortex of brain, cortex of liver and quadriceps femoris muscle from right posterior limb were prepared and stored under the same conditions like plasma.

\section{Determining of markers}

Tumor necrosis factor $\alpha$ (TNF- $\alpha$ ), interleukin 2 and 4 (IL-2 and IL-4) were assayed by an indirect Enzyme Linked Immunosorbent Assay (ELISA) using ELISA kits from Sigma-Aldrich. Caspase- 3 activity was determined by a kit from the same manufacturer. The assay was performed using instructions by manufacturer. Total level of antioxidants by Ferric Reducing Antioxidant Power (FRAP), reduced glutathione (GSH) and malondialdehyde by Thiobarbituric Acid Reactive Substances (TBARS) assay were done using earlier written protocols (12-14).

\section{Statistics}

Experimental data were processed for statistical differences between experimental groups in software Origin 9.1 (OriginLab Corporation, Northampton, MA, USA). One-way ANOVA in combination with Bonferroni test were chosen for determination of significance between experimental groups on probability levels p 0.05 and 0.01 .

\section{Results}

Animals used in the experiments were controlled for the whole time and no demise or any significant aberration in behavior occurred. After euthanasia, the cadavers exerted no pathological findings when dissected. The received biological samples were stored at $-80^{\circ} \mathrm{C}$ immediately after collection and the tested markers were determined in approximately two weeks after the collection.

No statistical significance was revealed when experimental data from IL-2, IL-4, FRAP and caspase-3 activity assay were processed. Compared to the insignificant results, significant differences were proven when TNF- $\alpha$ level in plasma (Fig. 1), GSH level in liver (Fig. 2), malondialdehyde level by TBARS in liver (Fig. 3) and muscle (Fig. 4) tissue were determined. TNF- $\alpha$ was increased on probability level $\mathrm{p}=0.01$ in animals receiving 20 and $50 \mu \mathrm{l}$ of FCA two and three days after application. The increase

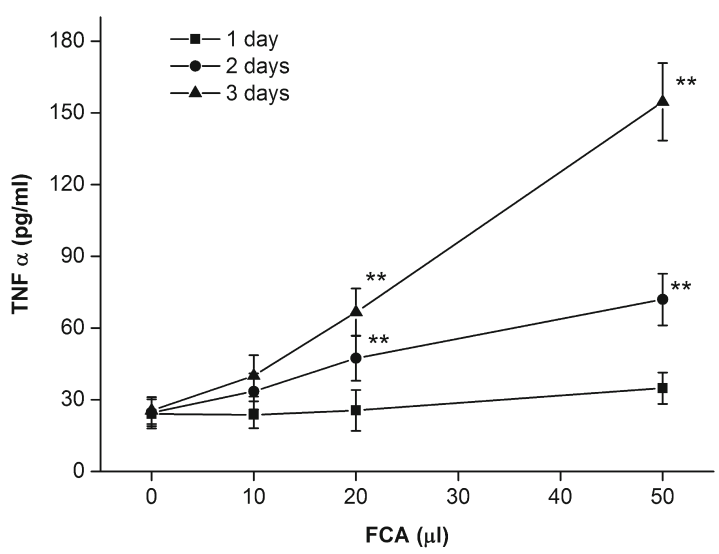

Fig. 1. Plasmatic concentration of tumor necrosis factor $\alpha$ (TNF $\alpha)$. Amount of applied Freund's complete adjuvant (FCA) is indicated on y axis. Error bars express standard deviation for $n=10$ and asterisks represents significance of difference between value and controls (FCA $=0 \mu \mathrm{l})$ for probability levels $0.05(*)$ and $0.01(* *)$.

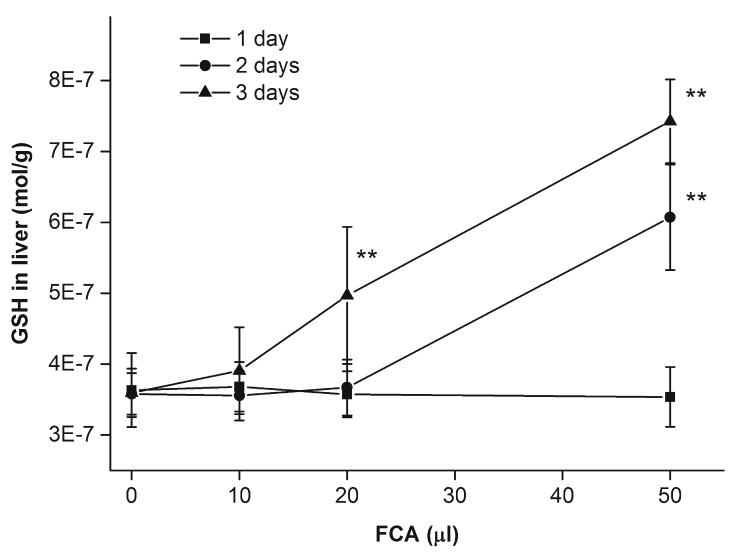

Fig. 2. Level of reduced glutathione (GSH) in liver tissue. Amount of applied Freund's complete adjuvant (FCA) is indicated on y axis. Error bars express standard deviation for $\mathrm{n}=\mathbf{1 0}$ and asterisks represents significance of difference between value and controls $(\mathrm{FCA}=0 \mu \mathrm{l})$ for probability levels $0.05(*)$ and $0.01(* *)$.

of TNF- $\alpha$ level was in a dose-response manner in the two time intervals where significance was revealed.

GSH increased in liver after application of the two upper doses of FCA in the last time interval. Though the increase was in a dose response manner in the last time interval, only one value (50 $\mu 1$ of FCA application) was significant in the interval two days. No significant finding for GSH was achieved when other organs were examined. Compared to GSH, malondialdehyde indicated by TBARS was significantly altered in both liver and muscles. While malondialdehyde was significantly increased in the liver from two days after application when the doses of FCA 20 and $50 \mu \mathrm{l}$ caused significant effect, three days after application FCA caused significant $(\mathrm{P}=0.01)$ increase of malondialdehyde level even in dose $10 \mu$ l of FCA. 


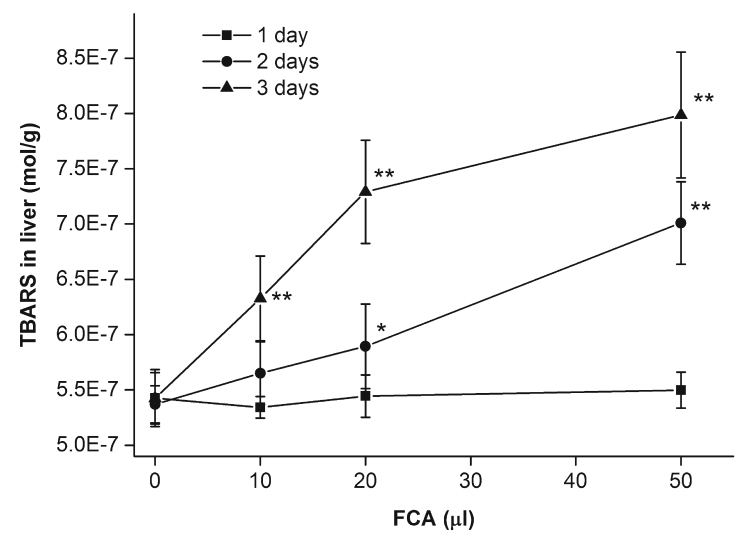

Fig. 3. Level of malondialdehyde represented as thiobarbituric acid reactive substances (TBARS) in liver tissue. Amount of applied Freund's complete adjuvant (FCA) is indicated on y axis. Error bars express standard deviation for $\mathbf{n}=\mathbf{1 0}$ and asterisks represents significance of difference between value and controls $(\mathrm{FCA}=0 \mu \mathrm{l})$ for probability levels $0.05(*)$ and $0.01(* *)$.

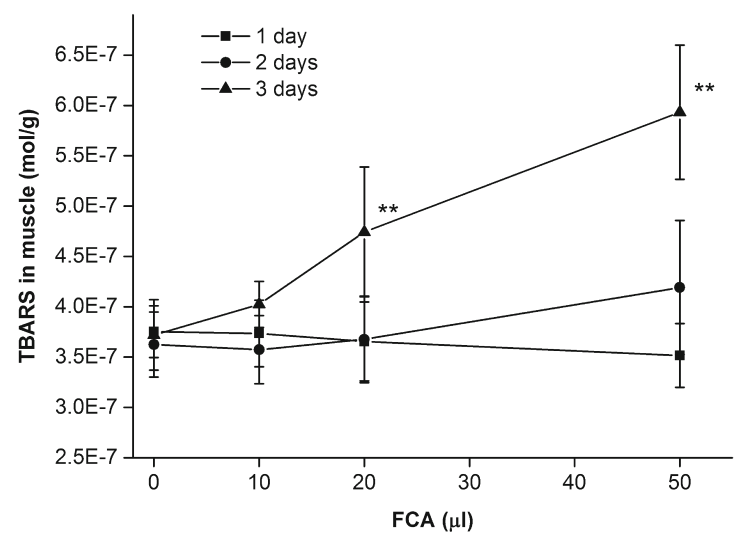

Fig. 4. Level of malondialdehyde represented as thiobarbituric acid reactive substances (TBARS) in muscle tissue. Amount of applied Freund's complete adjuvant (FCA) is indicated on y axis. Error bars express standard deviation for $\mathbf{n}=\mathbf{1 0}$ and asterisks represents significance of difference between value and controls $(\mathrm{FCA}=0 \mu \mathrm{l})$ for probability levels $0.05(*)$ and $0.01(* *)$.

\section{Discussion}

FCA is an adjuvant initiating inflammatory reaction which is a well-known fact (15). Experimental rheumatoid arthritis is a typical consequence of an uncontrolled inflammation initiated by FCA (16). Inflammation is in a tight link to oxidative stress as a causative process and to depletion of low molecular weight antioxidants as well $(17,18)$. In the results part, we showed both induction of inflammation because of the TNF $\alpha$ level increase and oxidative stress arising because of the significant augmentation of TBARS value representing malondialdehyde in both the liver and muscle tissue. When the datasets correlated one to each other, Pearson product moment correlation coefficient $(\mathrm{R})$ equal to
0.896 was found for TNF $\alpha$ and malondialdehyde in liver tissues taken three days after experiment beginning. R equal to 0.987 was determined for correlation between TNF $\alpha$ and malondialdehyde in muscle tissue. GSH was also in tight correlation to TNF $\alpha$ because R equal to 0.997 was calculated when GSH levels in livers taken in the last time interval were used.

We deduce that oxidative stress is a direct consequence of exposure to FCA. Increased level of GSH in the livers can be interpreted as fighting with oxidative stress by production of reduced glutathione. Better correlation of TNF $\alpha$ to GSH than to malondialdehyde in the livers is just a consequence of the antioxidant production. No significance in assayed IL-2, IL-4, FRAP and caspase- 3 activity determine that the markers are not sensitive to FCA or their role in pathologies related to FCA has lower relevance comparedto the malondialdehyde, GSH and TNF $\alpha$. The findings presented here support the conclusions by other researchers where antioxidants are discussed as suitable means for suppression of arthritis experimentally induced by FCA (19-21).

\section{Conclusions}

We conclude our study by an opinion that pathologies related to FCA are significantly mediated by oxidative stress in a tight junction with inflammation. Correlations between inflammation and malondialdehyde as well as glutathione are plausible confirmations of the idea. Results presented here also explain why FCA has a harmful effect when given above the threshold limit. It is because inflammatory reaction is followed by oxidative damage of cells as malondialdehyde is born just this way.

\section{References}

1. Toth LA, Dunlap AW, Olson GA, Hessler JR. An evaluation of distress following intraperitoneal immunization with freund adjuvant in mice Lab Anim Sci 1989; 39 (2): 122-126.

2. Alter G, Sekaly RP. Beyond adjuvants: Antagonizing inflammation to enhance vaccine immunity. Vaccine 2015; 33: B55-B59.

3. Guruprasad B, Chaudhary P, Choedon T, Kumar VL. Artesunate ameliorates functional limitations in freund's complete adjuvant-induced monoarthritis in rat by maintaining oxidative homeostasis and inhibiting cox-2 expression. Inflammation 2015; 38 (3): 1028-1035.

4. Chang XY, He H, Zhu LP et al. Protective effect of apigenin on freund's complete adjuvant-induced arthritis in rats via inhibiting p $2 \times 7 / n f-k a p p a b$ pathway. Chem-Biol Interact 2015; 236: 41-46.

5. Li R, Cai L, Hu CM, Wu TN, Li J. Expression of hedgehog signal pathway in articular cartilage is associated with the severity of cartilage damage in rats with adjuvant-induced arthritis. J Inflamm (Lond) 2015; 12.

6. Huang WY, Dai SP, Chang YC, Sun WH. Acidosis mediates the switching of $\mathrm{g}(\mathrm{s})$-pka and $\mathrm{g}(\mathrm{i})$-pkc epsilon dependence in prolonged hyperalgesia induced by inflammation. PLoS One 2015; 10 (5).

7. Kampman-van de Hoek E, Sakkas P, Gerrits WJJ, van den Borne J, van der Peet-Schwering CMC, Jansman AJM. Induced lung inflammation and dietary protein supply affect nitrogen retention and amino acid metabolism in growing pigs. Br J Nutr 2015; 113 (3): 414-425. 
8. Suri A, Calderon B, Esparza TJ, Frederick K, Bittner P, Unanue ER. Immunological reversal of autoimmune diabetes without hematopoietic replacement of beta cells. Science 2006; 311 (5768): 1778-1780.

9. Armentero MT, Levandis G, Nappi G, Bazzini E, Blandini F. Peripheral inflammation and neuroprotection: Systemic pretreatment with complete freund's adjuvant reduces 6-hydroxydopamine toxicity in a rodent model of parkinson's disease. Neurobiol Dis 2006; 24 (3): 492-505.

10. Broderson JR. A retrospective review of lesions associated with the use of freund's adjuvant. Lab Anim Sci 1989; 39 (5): 400-405.

11. Srivastava $S$, Singh $P$, Jha KK, Srivastava $S$, Khosa RL. Evaluation of anti-arthritic potential of the methanolic extract of the aerial parts of costus speciosus. J Ayurveda Integr Med 2012; 3 (4): 204-208.

12. Pohanka M. Caffeine alters oxidative homeostasis in the body of balb/c mice. Bratisl Med J 2014; 115 (11): 699-703.

13. Pohanka M, Sobotka J, Stetina R. Sulfur mustard induced oxidative stress and its alteration by epigallocatechin gallate. Toxicol Lett 2011; 201 (2): 105-109.

14. Pohanka M, Sobotka J, Jilkova M, Stetina R. Oxidative stress after sulfur mustard intoxication and its reduction by melatonin: Efficacy of antioxidant therapy during serious intoxication. Drug Chem Toxicol 2011; 34 (1): 85-91.
15. Castilhos LG, Rezer JFP, Ruchel JB et al. Effect of uncaria tomentosa extract on purinergic enzyme activities in lymphocytes of rats submitted to experimental adjuvant arthritis model. BMC Complement Altern Med 2015; 15.

16. Li R, Cai L, Hu CM, Wu TN, Li J. Expression of hedgehog signal pathway in articular cartilage is associated with the severity of cartilage damage in rats with adjuvant-induced arthritis. J Inflamm (Lond) 2015; 12.

17. Pohanka M. Role of oxidative stress in infectious diseases. A review. Folia Microbiol 2013; 58 (6): 503-513.

18. Pohanka M. Impact of melatonin on immunity: A review. Cent Eur J Med 2013; 8 (4): 369-376.

19. Yamada T, Abe M, Lee $\mathbf{J}$ et al. Muscle dysfunction associated with adjuvant-induced arthritis is prevented by antioxidant treatment. Skeletal Muscle 2015; 5 .

20. Arora R, Kuhad A, Kaur IP, Chopra K. Curcumin loaded solid lipid nanoparticles ameliorate adjuvant-induced arthritis in rats. Eur J Pain 2015; 19 (7): 940-952.

21. Ali EAI, Barakat BM, Hassan R. Antioxidant and angiostatic effect of spirulina platensis suspension in complete freund's adjuvant-induced arthritis in rats. PLoS One 2015; 10 (4). 